\title{
REPRESENTAÇÃO FEMININA NA CIÊNCIA: UM OLHAR SOB A PERSPECTIVA ÉTNICO-RACIAL NOS LIVROS DIDÁTICOS DE FÍSICA ${ }^{1}$
}

\author{
Jucilane Alves dos Santos, Universidade Federal de Campina Grande (UFCG), \\ jucilanealves@hotmail.com \\ Mirleide Dantas Lopes, Universidade Federal de Campina Grande (UFCG), \\ mirleide_dantas@yahoo.com.br
}

\begin{abstract}
RESUMO
A leitura imagética exerce relevante influência no processo de socialização. Neste sentido, buscamos na presente pesquisa analisar as imagens apresentadas em duas coleções de livros didáticos de Física do Ensino Médio. Em uma das coleções investigadas só haviam homens entre os autores, na outra havia uma mulher. Este fato também foi objeto de investigação. A pesquisa foi feita por meio de uma abordagem qualitativa e quantitativa, tentando identificar se as mulheres eram representadas de forma paritária e se estereótipos de gênero estavam sendo reproduzidos por meio das imagens ilustradas. Com o mesmo intuito, analisamos também a representação da mulher negra nestes espaços. Como resultado identificamos uma irrisória representação feminina livros didáticos investigados, especialmente da mulher negra. Observamos também que na coleção que possuía uma mulher entre os autores, a representação feminina além de ser menor, estava mais associada às atividades relativas aos cuidados com o lar. Tal constatação nos leva a crer que apesar de termos avançado na direção de uma educação mais igualitária, muito ainda temos que fazer neste sentido.
\end{abstract}

PALAVRAS-CHAVE: Representação feminina; Livros didáticos; Mulheres negras.

\section{FEMININE REPRESENTATION IN SCIENCE: A LOOK UNDER THE ETHNIC-RACIAL PERSPECTIVE IN PHYSICS TEXTBOOKS}

\begin{abstract}
We analyze in this work the images presented in two collections of Physics textbooks. The research was done through a qualitative and quantitative approach, trying to identify if women were represented in an inclusive and equality way. The representation of the black woman was also analyzed. We have identified an unsatisfactory female representation, especially of the black woman.
\end{abstract}

KEYWORDS: Female representation; Didactic books; Black women.

${ }^{1} \mathrm{O}$ presente trabalho (não) contou com apoio financeiro de nenhuma natureza para sua realização. 


\section{REPRESENTACIÓN FEMENINA EN LA CIENCIA: UNA MIRADA BAJO LA PERSPECTIVA ÉTNICO-RACIAL EN LOS LIBROS DIDÁCTICOS DE FÍSICA}

\section{RESUMEN}

Analizamos en este trabajo las imágenes presentadas en dos colecciones de libros didácticos de Física. La investigación se realizó desde un enfoque cualitativo y cuantitativo, tratando de identificar si las mujeres eran representadas de forma inclusiva e igualitaria. La representación de la mujer negra también fue analizada. Identificamos una insatisfactoria representación femenina, especialmente de la mujer negra.

PALABRAS CLAVES: Representación femenina; Libros didácticos; Mujeres negras.

\section{INTRODUÇÃO}

Na sociedade contemporânea somos constantemente bombardeados por imagens que exibem informações por meio de inúmeras fontes, sejam elas charges de rua, panfletos de propagandas ou até mesmos os livros. Essas imagens caracterizam-se como uma linguagem não verbal e têm um enorme impacto na vida das pessoas que lidam diretamente com elas, tornando-se um forte meio de comunicação visual.

O livro didático, por exemplo, é uma poderosa fonte de informações visuais que os alunos e alunas utilizam durante toda a formação escolar. Neste, os conteúdos são trabalhados não apenas através da escrita, mas de forma integrada com as imagens apresentadas, que para além da função lúdica de tornar mais substancial a discussão realizada, também se configuram como um fundamental instrumento de ensino-aprendizagem.

Conforme Kuhn (1998, p. 29), os livros se tornaram mais populares no início do século XIX. Na atualidade eles continuam sendo referência no processo de difusão do conhecimento científico, seja através de sua utilização nos grandes laboratórios e centros de pesquisa, ou até mesma na formação dos estudantes da Educação Básica. Através deles os discentes terão contato com textos verbais e imagéticos, podendo assim avaliar os conteúdos de relevo que estão sendo investigados em sua época.

Diante da complexa e fundamental relevância do livro como meio de socialização do conhecimento, cabe destacar que no tocante à elaboração destes, em especial os livros 
didáticos, é essencial que os autores tenham a sensibilidade de desenvolver junto aos leitores uma formação mais ampla, que os conduza a uma leitura para além das palavras, uma leitura que lhes dê a possibilidade de refletir sobre as práticas sociais historicamente construídas.

Neste sentido, objetivamos no presente artigo discutir a sub-representação feminina na ciência, em especial na Física, e como o livro didático pode contribuir para desconstruir alguns dos estereótipos que tanto invisibilizam e sobrecarregam a vida das mulheres. Tal discussão será feita tomando como referência duas coleções de livros didáticos de Física do ensino médio, ocasião em que também será analisada a representação da mulher negra nos referidos livros. Previamente faremos uma breve discussão histórica sobre a participação da mulher na ciência, com o objetivo de tentar identificar a gênese dessa sub-representação.

\section{A MULHER NA HISTÓRIA DA CIÊNCIA}

A trajetória da mulher ao longo dos tempos foi marcada por preconceitos que definiam qual deveria ser o seu lugar na sociedade e como elas deveriam se comportar. Tratadas como o sexo frágil, elas carregaram por séculos todo o fardo de uma sociedade machista e patriarcal, que as confinava ao espaço privado. Neste sentido, a divisão sexual do trabalho, que até hoje serve de sustentáculo ao modelo capitalista, atribuía ao homem o papel de provedor da família, aquele que vai a público realizar o "trabalho duro". À mulher caberia "apenas" a responsabilidade sobre o lar, o trabalho doméstico, a assistência aos filhos e a incumbência de receber o marido com comida quente e uma família bem organizada. Nada fora do padrão seria aceitável (KERGOAT, 2016, p. 17).

As mulheres não poderiam ser pesquisadoras e as poucas que se atreviam a investigar as ciências, estudavam no âmbito familiar, eram de famílias abastadas e pertencentes as classes sociais mais elevadas. De todo modo, quando conseguiam espaço em alguma reunião de acadêmicos era sempre acompanhada pelo marido, companheiro ou tutor, não tendo suas contribuições evidenciadas, nem registradas para a posteridade, a notoriedade não lhes pertencia. Neste sentido, Schiebinger (2001, p. 41) afirma que, "A despeito de raça, credo, identidade sexual ou mérito, todas as mulheres - por nenhuma razão outra que seu sexo foram proibidas de estudar nas universidades européias desde a fundação das universidades no século XI até o fim do século XIX.” Este episódio de segregações certamente concorreu para retardar o desenvolvimento científico em sua totalidade. 
A Revolução Científica, ocorrida em meados do século XVII, fez com que um maior número de mulheres despertasse interesse pela alfabetização e, consequentemente, pela ciência, era uma revolução irreversível. Entretanto, na mesma proporção, também passou a massacrar com maior proeminência aquelas que eram taxadas como bruxas, mulheres em sua maioria pobres e sozinhas, que dominavam técnicas milenares, a exemplo da manipulação de ervas medicinais (TOSI, 1998, p. 372).

Diversos acadêmicos, entre eles, Aristóteles, Rosseau e mais recentemente Darwin, contribuíram para difundir a ideia de inferiorização da mulher enquanto sujeito e reduzi-la à condição de um homem incompleto, ou cuja evolução parou. A notoriedade desses e de tantos outros intelectuais, em diferentes períodos históricos, legitimava o discurso, à época hegemônico, de que à mulher não caberia o espaço público, tampouco a construção das ciências (GUIMARÃES; ARAS, 2016, p. 27).

No entanto, mesmo com todas as intempéries postas, silenciosamente as mulheres foram se insurgindo no cenário científico. Alguns episódios históricos, a exemplo da Revolução Francesa, foram bastante influentes nesse sentido (TOSI, 1998, p. 379). Apesar de muitas terem sido posteriormente rechaçadas, houve uma considerável participação feminina na construção dos ideais de igualdade, liberdade e fraternidade, que também tiveram um papel decisivo na luta por uma vida mais digna e inclusiva para as mulheres.

Faz-se importante destacar que mesmo invisibilizadas e subjugadas pelo modelo de sociedade vigente, algumas mulheres ainda conseguiram ultrapassar as barreiras legais e sociais impostas, dando relevantes contribuições à construção do conhecimento científico e descaracterizando assim a falácia de que o sexo feminino era inferior e incapaz de produzir conhecimento. Um exemplo bastante emblemático, entre tantas outros que poderíamos citar, foi o caso da física polonesa Marie Curie, que apesar de ter ganho dois prêmios nobéis, enfrentou toda a sorte de preconceitos para alcançar o devido reconhecimento (GONÇALVES-MAIA, 2012, p.24).

A mobilização mais incisiva, no sentido de ampliar a participação feminina no espaço público, veio com o movimento feminista. Iniciado no fim do século XIX, a princípio reivindicando o direito ao sufrágio universal, o referido movimento foi quem questionou de forma mais contundente as estruturas sociais e seus preconceitos fundantes relativos às mulheres (PINTO, 2010, p. 15). Na medida em que o movimento foi ganhando força, outras 
demandas foram sendo reivindicadas, entre elas ações que viabilizavam uma maior participação das mulheres na ciência, bem como medidas que diminuíssem sua invisibilidade no âmbito acadêmico.

$\mathrm{Na}$ contemporaneidade as barreiras legais impostas foram minimizadas, porém as barreiras sociais, historicamente construídas, ainda estão erguidas e se fazem presentes no cotidiano daquelas que ousam se aventurar em áreas cuja presença masculina é majoritária.

\section{A REPRESENTAÇÃO FEMININA}

Ao contrário de um passado não muito longínquo, em que as mulheres sequer poderiam estudar em Instituições de Ensino Superior (IES), atualmente elas ocupam mais de $50 \%$ das vagas nas IES's (OLINTO, 2011, p. 72). Certamente isso se configura como um considerável avanço, no entanto, existem algumas áreas, a exemplo da Física, em que a representação feminina é irrisória (AGRELLO; GARG, 2009, p. 01). Essa sub-representação, aparentemente inofensiva, traz grandes consequências para o desenvolvimento científico, pois sendo este uma construção humana, é interessante que seja edificado por múltiplos olhares, pela diversidade, e não exclusivamente por homens, brancos e abastados.

A Física ainda é um campo científico predominantemente masculino e as poucas mulheres que ousam adentrar nessa área, costumeiramente, têm suas atuações colocadas à prova (LIMA, 2013, p. 886). Este mecanismo, ainda que de forma sutil e naturalizada, age no sentido de prover a manutenção do status quo, que delimita quem é o sujeito capaz de produzir conhecimento científico. $\mathrm{O}$ fato é que esta ciência carrega em sua essência o rótulo de ser dura, de pensamento lógico e abstrato, associada a um trabalho árduo e competitivo, não condizente com a ideia de feminilidade socialmente construída.

As colocações apresentadas encontram respaldo em Bourdieu (2012, p. 07), quando o autor define o paradoxo da dóxa, que seria a naturalidade e a consequente falta de indignação para com a ordem mundial estabelecida, uma vez que ela está alicerçada em relações de dominação e condições que deveriam ser intoleráveis, mas que no entanto são frequentemente vistas como aceitáveis e até mesmo naturais. O autor ainda descreve como essas relações se estruturam, 
exercida em nome de um princípio simbólico conhecido e reconhecido tanto pelo dominante quanto pelo dominado, de uma língua (ou uma maneira de falar), de um estilo de vida (ou uma maneira de pensar, de falar ou de agir) e, mais geralmente, de uma propriedade distintiva, emblema ou estigma, dos quais o mais eficiente simbolicamente é essa propriedade corporal inteiramente arbitrária e não predicativa que é a cor da pele. (BOURDIEU, 2012, p. 08)

É evidente que tais relações imperam e ditam as regras de convivência e atuação em sociedade. Para reverter essa lógica que tanto invisibiliza as mulheres, sobretudo as mulheres negras, é preciso promover espaços de discussão, problematizar o mundo a nossa volta, indagar a aparente naturalidade com a qual as representações são feitas, desenvolver um posicionamento crítico e analítico sobre as diferentes manifestações sociais que nos rodeiam e que de forma naturalizada, legitimam a lógica de dominação masculina.

O ser humano tem um fascínio enorme por representação. Nós nos reconhecemos nos símbolos, e seus respectivos signos, que nos são apresentados. Assim como, internalizamos, mesmo que de forma tácita, o significado da ausência de determinadas representações. Neste sentido, precisamos problematizar essas ausências e reclamar ações afirmativas que as tornem menos expressivas.

É nesta perspectiva que passamos a discutir a importância da representação feminina nos livros didáticos. As imagens neles apresentadas vão, ao longo dos anos, construindo na estrutura cognitiva dos alunos e alunas padrões de referência que influenciam na maneira como se constroem as relações sociais. Neste sentido, é interessante que os livros didáticos não se limitem apenas a ilustrar imagens femininas, mas que tragam imagens que falem de possibilidades, mostrando que as mulheres podem exercer diferentes profissões, e que, mesmo invisibilizadas, elas conseguiram dar relevantes contribuições para a construção do conhecimento científico. Se do contrário, as imagens apenas reproduzirem os estereótipos sociais vigentes, apresentando mulheres no espaço doméstico, ou em profissões taxadas como femininas, elas em nada contribuirão para a construção de uma sociedade mais justa e igualitária.

A representação feminina nos livros didáticos de Física, por meio de imagens de mulheres em laboratórios por exemplo, é de suma importância, pois permite que as meninas compreendam que a ciência não é feita pela hierarquização do sexo biológico e possam, eventualmente, se reconhecerem exercendo aquela profissão, algo que infelizmente não 
condiz com a realidade atual. Infelizmente, no Ensino Médio as garotas não têm despertado interesse em profissionalizar-se nessa área. Podemos compreender tal realidade a partir da leitura de Pinto, Carvalho e Rabay (2014, p. 247), em que afirmam, "As relações de gênero, fortemente construídas, destinam meninos/homens e meninas/mulheres a constituírem grupos segregados voluntariamente ou não."

Segundo Rosa e Silva (2015, p. 85), "Um dos objetivos do ensino de ciências é promover o acesso ao conhecimento científico produzido pela humanidade ao longo dos anos para todas as pessoas, independentemente de raça, credo religioso, sexo, etc.", e para que esta afirmativa se concretize é preciso tornar o conhecimento mais democrático, mais representativo.

Desta feita, faz-se urgente promover discussões que viabilizem a inclusão social das mulheres, sendo estas entendidas em sua pluralidade. Tais diálogos precisam ser realizados nos mais diferentes níveis de ensino, em especial no Ensino Médio, momento em que os meninos e meninas estão se preparando para escolher suas respectivas profissões e adentrarem no mercado de trabalho. Um olhar mais sofisticado quanto à elaboração dos livros didáticos precisa ser aprimorado, na tentativa de desconstruir este modelo de sociedade que tanto massacra e castra os anseios e perspectivas femininas.

\section{O PERCURSO METODOLÓGICO}

No presente trabalho realizamos uma análise comparativa, por meio de uma pesquisa bibliográfica, em duas coleções de livros didáticos de Física do ensino médio regular (volumes 1, 2 e 3), que estão previstas no Plano Nacional do Livro Didático (PNLD) de 2015, 2016 e 2017. Para melhor interpretação dos dados levantados, realizamos uma abordagem qualitativa e quantitativa (PRODANOV; FREITAS, 2013, p. 70).

Foram observados e analisados todos os tipos de imagem, nos livros das duas coleções, sendo elas, desenhos, fotografias, quadrinhos, desde que fosse possível distinguir o sexo que estava sendo ilustrado.

A primeira coleção investigada foi escrita apenas por homens, a coleção Física Ciência e Tecnologia, cujos autores são Carlos Magno A. Torres, Nicolau Alberto Ferraro, Paulo Antonio de Toledo Soares e Paulo Cesar Martins Penteado, ela foi publicada pela editora 
Moderna, em $3^{\text {a }}$ edição, no ano de 2013. A segunda coleção, Física contexto e aplicações, foi escrita por um homem e uma mulher, Antônio Máximo Ribeiro da Luz e Beatriz Alvarenga Álvares, ela foi publicada pela editora Scipione, em $1^{\mathrm{a}}$ edição, no ano de 2013. Entre outras questões, essas coleções foram escolhidas por serem bastante utilizadas nas escolas públicas da Paraíba, estado em que a pesquisa foi realizada.

Especificamente a análise qualitativa foi feita observando a maneira como as mulheres eram representadas, investigando se os livros didáticos utilizados na pesquisa as apresentavam em diferentes espaços de atuação social, enquanto cientistas por exemplo, ou apenas traziam figuras ilustrando e reproduzindo velhos estereótipos atrelados ao sexo feminino. Também buscamos analisar se o fato de uma das equipes de autores ter uma mulher em sua composição poderia influenciar na maneira como as mulheres eram representadas nos livros analisados.

A abordagem quantitativa foi feita calculando os percentuais das imagens de homens e mulheres em todos os livros das diferentes coleções e, em seguida, contabilizando quais das duas coleções trazia maior valor percentual de imagens femininas. Também foi analisado se o fato de ter uma mulher no corpo de autores de uma coleção poderia influenciar nesse percentual.

Entre as imagens femininas analisadas buscamos identificar se as mulheres negras também estavam sendo representadas, uma vez que uma parcela significativa da população brasileira declara-se negra ou parda, no entanto, esta parcela é costumeiramente invisibilizada, em especial se for mulher.

\section{AS OBSERVAÇÕES REALIZADAS}

De modo geral, observamos por meio da presente pesquisa que nos livros investigados a representação feminina se mostrou bastante irrisória e longe de ser paritária. Além disso, muitos dos estereótipos sociais que legitimam práticas sexistas são reproduzidos com certa frequência. Outra observação feita foi que pouquíssimas imagens retrataram a mulher fazendo ciência, o que concorre para reproduzir a ideia naturalizada de elas não são capazes de produzir conhecimento científico.

Especificamente, constatamos que na coleção escrita apenas por homens havia 74,5\% de imagens masculinas, para $25,5 \%$ de imagens femininas. Já na coleção que tinha uma 
mulher como autora, o percentual de imagens masculinas era relativamente maior, cerca de $86,1 \%$, enquanto femininas, míseros $13,9 \%$. Este dado foi surpreendente, porque ele destoa um pouco das hipóteses levantadas. No entanto, serve para chamar a atenção de que mesmo tendo uma mulher em espaços comumente ocupados por homens, se ela não reconhecer a importância de aumentar a visibilidade feminina, por meio dessas leituras imagéticas, o fato de um livro de Física ter uma mulher no seu corpo de autores será pouco relevante.

Outro dado intrigante observado foi que na primeira coleção, escrita apenas por homens, havia um número maior de imagens de mulheres cientistas, sendo possível afirmar que, mesmo contrariando nossas expectativas, este grupo de autores se mostrou mais sensível à representação de cientistas mulheres nos livros didáticos de Física. Neste sentido, os autores trazem a fotografia de duas físicas notáveis, Marie Curie e Lise Meitner. A primeira recebeu duas vezes o prêmio Nobel, um em Física e o outro em Química, já a segunda, apesar de ter dado relevantes contribuições à pesquisa que explicou a fissão nuclear, ela não foi agraciada com o referido prêmio, sendo este entregue apenas aos seus colaboradores (MIZRAHI, 2005, p. 492).

Na primeira coleção também é mais comum a representação de mulheres praticando esportes em áreas que requerem força e precisão, a exemplo do lançamento de martelo e tiro com arco. No entanto, quando a rotação, conteúdo muito trabalhado na Física, passou a ser investigada, a figura da bailarina foi ilustrada com bastante frequência para exemplificar.

Também é importante registrar que na primeira coleção, escrita apenas por homens, não foram encontradas imagens de mulheres realizando afazeres domésticos. Já no caso da segunda coleção, isso foi bastante perceptível em duas imagens, uma em que a mulher estava passando roupas e na outra cozinhando. $\mathrm{O}$ detalhe é que não tem nenhuma imagem masculina similar, com o objetivo de mostrar que o homem também pode se responsabilizar pelos afazeres domésticos.

Quanto à representação da mulher negra, tanto na primeira, quanto na segunda coleção, foi apresentado um número irrisório de imagens. Em todos os três livros analisados, observamos apenas 2 imagens de mulheres negras, em cada coleção. Entretanto, cabe destacar que apesar do número insatisfatório, as imagens apresentadas traziam informações bastante significativas. Em uma delas, por exemplo, a mulher negra mostrava a um homem branco 
como é possível abrir uma garrafa sem necessariamente fazer uso da força, evidenciando assim a sua capacidade de raciocínio.

\section{CONCLUSÕES}

Os resultados ora apresentados sinalizam a importância de se ampliar a discussão sobre gênero e representatividade feminina nos livros didáticos, uma vez que, mesmo quando há mulheres entre o corpo de autores, essa representação ainda é insatisfatória e sexista.

Outro dado intrigante é que mesmo na coleção em que há uma mulher no corpo de autores, o número de imagens femininas é bem menor, quando comparado à coleção escrita apenas por homens, o que indica que talvez a autora não se identifique com a temática, reforçando assim a necessidade de discuti-la nos mais distintos espaços de educação formal e não formal.

Em se tratando das mulheres negras, essa representação é ainda menos expressiva, o que ratifica a dupla invisibilidade que esta categoria costuma sofrer em nossa sociedade. No entanto, as poucas imagens trazidas falam da capacidade da mulher negra.

De modo geral, observamos que há uma sensível mudança no sentido de qualificar a representação feminina nos livros didáticos investigados, no entanto, ainda há um longo caminho a ser percorrido para que essa mudança possa contribuir para reconstruir nosso modelo de sociedade que ainda é patriarcal e machista. Para tanto, é preciso mostrar aos nossos meninos e meninas que ambos são capazes de cuidar das responsabilidades do lar, bem como de contribuir para a construção do conhecimento científico, especialmente na Física. 


\section{REFERÊNCIAS BIBLIOGRÁFICAS}

AGRELLO, D. A.; GARG, R. Mulheres na física: poder e preconceito nos países em desenvolvimento. Revista Brasileira de Ensino de Física, v. 31, n. 1, 2009.

BOURDIEU, P. A dominação masculina. Trad. Maria Helena Kühner. 11 ed. Rio de Janeiro: Bertrand Brasil, 2012.

GONÇALVES-MAIA, Raquel. Marie Sklodowska Curie: imagens de outra face. São Paulo: Editora Livraria da Física, 2012.

GUIMARÃES, S. G., ARAS, L. M. B. de. A ciência e seus discursos: a exclusão das mulheres na medicina. In: SARDENBERG, C. M. B.; MINELLA, S. L. (Orgs). Gênero e ciências: as mulheres em novos campos. Salvador: EDUFBA/NEIM, 2016. p. 19-40.

KERGOAT, D. O cuidado e a imbricação das relações sociais. In: ABREU, A. R. P. et al. (Orgs). Gênero e trabalho no Brasil e na França. Trad. Carol de Paula. 1 ed. São Paulo: Boitempo, 2016. p. 17-26.

KUHN, T. S. A estrutura das revoluções científicas. Trad. Beatriz Vianna e Nelson Boeira. 5 ed. São Paulo: Ed. Perspectiva, 1998.

LIMA, B. S. O labirinto de cristal: as trajetórias das cientistas na Física. Estudos Feministas, Florianópolis, v. 21, n. 3, p. 883-903, setembro-dezembro/2013.

MIZRAHI, S. S. Mulheres na Física: Lise Meitner. Revista Brasileira de Ensino de Física, v. 27, n. 4, p. 491 - 493, 2005.

OLINTO, G. A inclusão das mulheres nas carreiras de ciência e tecnologia no Brasil. Inc. Soc., Brasília, DF, v. 5 n. 1, p.68-77, jul./dez. 2011.

PINTO, C. R. J. Feminismo, história e poder. Revista de Sociologia e Política, v.18, n.36, 2010.

PINTO, E. J. S.; CARVALHO, M. E. P. de; RABAY, G. Gênero: um fator condicionante nas escolhas de cursos superiores. In: Encontro da Rede Feminista Norte e Nordeste de Estudos e Pesquisa sobre a Mulher e Relações Gênero (REDOR), 18., 2014, Recife. Anais ... Recife, 2014. p. $233-249$.

PRODANOV, C. C.; FREITAS, E. C. Metodologia do trabalho científico: métodos e técnicas da pesquisa e do trabalho acadêmico. 2. ed. Novo Hamburgo: Feevale, 2013.

ROSA, K.; SILVA, M. R. G. da. Feminismos e ensino de ciências: análise de imagens de livros didáticos de Física. Revista Gênero, v.16, n.1, p. 83 - 104, 2 sem. 2015. 
SCHIEBINGER, L. O feminismo mudou a ciência?. Trad. Raul Fiker. Bauru - SP: EDUSC, 2001.

TOSI, L. Mulher e ciência: a revolução científica, a caça às bruxas e a ciência moderna. Cadernos Pagu. v. 10. p. 369-397, 1998. 